\title{
Application of Clustering Techniques Based on the Balance of Brain Functions in Learning Writing Narration in Ponorogo Elementary School
}

\section{R. Wardiani1, S. Suwandi², Andayani², and Budiyono ${ }^{1}$}

${ }^{1}$ Indonesian Language Education Study Program, College of Teacher Training and Education Teachers Association of the Republic of Indonesia, Ponorogo, East Java, Indonesia

${ }^{2}$ Doctoral Program of Graduate Education in Indonesia Language, Sebelas Maret University, Surakarta, Central Java, Indonesia

${ }^{3}$ Doctoral Program of Mathematics Education, Sebelas Maret University, Surakarta, Central Java, Indonesia

\section{Abstract}

Writing is communicating thoughts and ideas. The objective of the study was to

Corresponding Author:

R. Wardiani

ririenw@student.uns.ac.id

Received: 6 April 2018

Accepted: 3 May 2018

Published: 26 July 2018

Publishing services provided by Knowledge $\mathrm{E}$

(c) R. Wardiani et al. This article is distributed under the terms of the Creative Commons

Attribution License, which permits unrestricted use and redistribution provided that the original author and source are credited.

Selection and Peer-review under the responsibility of the ISLLE 2017 Conference Committee. describe the use of clustering techniques. The application of clustering techniques is supported by a balanced brain activation combined with a guiding question. This research was conducted at Elementray School (SDN) 2 Tonatan Kabupaten Ponorogo. Students are 29 people, held for 2 months. The research method used is action research. The writer uses observation, interview, document analysis, and composition tests for data collection. The analytical techniques used are interactive analysis and comparative descriptive. The results showed that clustering techniques based on balancing brain function can improve the level of students' narrative writing, which is illustrated in the mastery percentage progress in every cycle. Cycle 1 is $34 \%$, cycle 2 is $48 \%$, and cycle 3 is $83 \%$. It is also illustrated that there is progress in every aspect of narrative writing.

Keywords: balancing brain function, clustering technique, learning, writing narrative

\section{Introduction}

Writing skills is part of learning Bahasa Indonesia. This skill has an important role in the process of student learning development. This is in line with the explanation of Curriculum 2013 on the position of Indonesian subjects as an advocate of other subjects. The learning objectives of Bahasa Indonesia are that students are skillful in listening, reading, speaking, and even writing skills. It is important for students to 
master these skills from primary education. Writing skills are closely related to reading skills.

In terms of international research results, the 2015 Program for International Student Assessment (PISA) stated that students' reading ability in Indonesia ranked 69th out of the 76 countries surveye [1]. For reading competence, in particular, the subscale used is the ability of students to retrieve information, interpret text, and reflecti text [2]. These results encourage attempts to improve literacy skills. Literacy skills can be developed by enhancing writing skills.

Writing is the communication of thoughts and ideas [3]. Writing is a complex skill. Furthermore. The development of writing ability is influenced by motivation and selfregulation [4]. The skill of writing is essentially indirect communication with the reader. An explanation of writing is given in more detail by Chandler as follows [5]: Writing is someone's communication with someone with a purpose, which might include: (1) reporting something; (2) keeping in touch; (3) recording facts, thoughts, or feelings; (4) clarifying an idea for self-interest. Further, that writing is a process of thinking within the dimensions of discovery [5].

Based on the view of the experts mentioned above it can be concluded that writing is a process of thinking with the aim of conveying to/communicating with others. Writing skill is a skill that prioritizes creativity influenced by motivation and self-regulation. Writing skills are skills that require capital obtained through references, whether read, heard, or viewed.

Writing is a skill that must be learned and practiced [6]. They conducted a study in a Mexican elementary school. Smith's research was conducted both inside and outside school. It involved family and community members. The conclusion drawn from Smith's study is that writing learning should be tailored to the needs of students. The background of a student's social context can affect his/her writing skills. Referring to the results of Smith's research, it is proposed that the condition and way of thinking of students are the main things to note in writing.

A brief overview of the stages of the writing process is given by Tompkins [7], who presents five stages: (1) prewriting, (2) drafting, (3) revising, (4) editing, and (5) publication/sharing. The writing process begins with the prewriting, writing, and postwriting stages. The process of writing requires the work of the brain in mind to pour the ideas stored in the mind. It is a resource or capital to be able to issue ideas. This idea is certainly supported by the ability to choose a genre, rhetoric, diction, and way of presentation in addition to having to build an emotional self and readers. This requires a balanced brain work. 
The writing skills in this study are focused on writing narratives. The narrative genre is chosen because writing narratives is the most basic skill that children should master [8]. The ability to write narrative is the first step in teaching the writing process for students. Importance of acquiring writing skills through the writing of personal narratives [8]. The research was conducted in a rural elementary school in western New York State, America. Martin concludes that writing a personal narrative in elementary school is a necessary basis for writing. The skills developed in writing personal narratives are the ability to organize, the use of spelling, word choice, and the ability to edit or revise. Students can use narrative writing to create entertaining stories [9]. They recounted famous stories, wrote connections, and new episodes for favorite characters, and could also write their own stories. Students can take advantage of all the sensory capabilities it has. The students' sensory capabilities are maximized when supported by enjoyable learning.

The research of Roger disclosed the difference in in how both hemispheres store and process information [10]. The results of these studies reinforce the existence of different functions between the two hemispheres. Many experts argue that the left brain is the IQ (Intelligence Quotient) controller, while the right brain plays an important role in the development of EQ (Emotional Quotient). The brain has several important roles in the process of creativity, such as creativity, imagination, and intelligence. These components have a lot of potential in the creative process, and these three keywords are closely related to the function of the brain. In terms of creativity ability, the power of imagination is a function of the right brain. Intelligence is a function of the brain in general with both right- and left-brain functions.

For the above reasons, appropriate writing learning techniques are needed. There are researches on writing techniques study about writing skill, which can be developed with the mnemonic POWER technique (Planning, Organizing, Writing, Editing, Rewriting), which is emphasized on E (Editing) [11]. This study shows the success of students at the elementary level because it integrates with other sciences. This writing study is based on inquiry activities with a focus on editing activities. This editing activity begins with scientific investigation activities developed through observation activities by collecting facts in the form of data, describing facts and data in a convincing way. The next activity is sharing and review writing. This writing is expected as a communication effort in accordance with the expected scientific principles.

There is a similar study to that of Fazio performed by Smitherman and Girard [12]. His research offers a technique by making a bridge between learning to write and creative writing. Institutional and faculty administrators across disciplines are not always 
convinced that the program delivers students intelligently to move the overall idea of writing from one program to another. The presentation of the results of this study introduces the idea of using creative writing models as an alternative to the discussion of composition theory by writing the first year of the student. This model will help students achieve a deeper understanding of a particular field of study while preparing them for writing. The bridge is called "craft criticism." Craft criticism is a bridge between creative writing and learning materials. Learning about creative writing and writing in a particular field will result in good writing skills.

Based on these two studies, writing technique aims to facilitate the expression of ideas and ideas. This study seeks to use other techniques by optimizing the ability of both hemispheres in a balanced way with clustering techniques. Balancing brain function makes it easier for students to express their ideas. Feelings, emotions, and imagination, which are the right-brain function of expression, are aided by the workings of the left brain. Writing is an entire brain activity that uses the right hemisphere (emotional) and the left hemisphere (logic) [13]. A fun technique based on balancing the right brain and the left brain is clustering technique.

\section{Methods}

\subsection{Theory}

Clustering is a right-dominated activity of the brain. The term "clustering" refers to the concept of Rico [14], which states that clustering is a technique for exploring ideas and associations that belong to the topic. In line with Rico's concept, De Potter explains that clustering is a way of sorting out ideas and pouring them onto paper as quickly as possible [13], without consideration. The clustering technique has several steps in its creation: 1) starting with the circled core word, 2) releasing the judgment and letting it flow with the connections coming to the head, 3 ) noting quickly (each in its own circle and radiating out from the center to every direction, 4) connecting any new words or phrases with lines to the previous circle, 5) when the idea breaks, start again from the center core and radiate out, 6) stopping grouping, 7) no hesitation in using only some ideas from clustering already made.

Learning must have a sequence of activities (syntax) that is a series of stages in a learning model that will be used [15]. In general, the sequence of learning activities using clustering techniques is stated as follows: 1) Emotion ignition; this phase provides stimulants of idea discovery with classroom conditioning and student emotion. 
Emotion ignition is activated by the right brain. Right-brain activation can be a media image, concrete objects, and audiovisual media. 2) Clustering is a continuation of the idea by clustering ideas in the form of clusters that connect left- and right-brain activity with symbols, marks, and colors. 3) Expressing; draft writing based on the clustering process. 4) Editing and evaluating. 5) Reflection, analyzing the results of writing the narrative of students who have been edited and followed by making the design of the next activity; 6) Displaying. These six steps become the basis for learning to write a narrative perspective balancing brain function.

\subsection{Research methods}

The purpose of this study is to describe the use of clustering techniques based on balancing the right- and left-brain functions in narrative writing lessons. This research uses action research methods. This research was conducted in SDN 2 Tonatan of Ponorogo Regency. The subjects of this study are 29 students from the $4^{\text {th }}$ grade. The study was applied from 17 January to 31 March 2017. The techniques used for data collection were observation, interviews, and performance tests. The interviews were conducted with teachers and students, while observation was carried out during the lesson. The instruments used were interview guides, teacher and student observation guidelines, and performance tests in the form of writing competence tests. Aspects of assessment of narrative writing tests include content, organizational content, vocabulary, grammar, and spelling.

Data analysis was done by interactive analysis and comparative descriptive. This research was conducted over three cycles. Each cycle contained four stages: planning, action, observation, and reflection. The analysis of narrative writing skills is based on success criteria in both categories for every aspect and is eligible for complete learning. Personal mastery is achieved if the student has achieved a score of 75 . Classical mastery is achieved if $80 \%$ of all students have been completed personally. Learning to write narratives is said to be marked by a change towards improving narrative writing skills in $4^{\text {th }}$ grade students.

\section{Results}

This study was conducted over three cycles. In the first cycle, the writer uses clustering techniques using the image media sandals as a balancing activity of right- and leftbrain function. Clustering is assisted by a question word guide (what, who, when, 
where, how, and why). The use of image media is an activity of emotional ignition, which is a stimulation activity of right-brain activation. This activity is balanced with the structural activities of making the framework by developing the word question. To make it easier for students to create a narrative essay the teacher conditioned the story based on sad and happy experiences. Next the teacher made a group of sad stories and happy stories. Students develop sad or happy stories based on clustering results for sad and happy stories. The results showed that clustering techniques based on balancing brain function can improve the competence of student narrative writing, which is illustrated in the mastery percentage progress in every cycle. Cycle 1 is $34 \%$, cycle 2 is $48 \%$, and cycle 3 is $83 \%$. This is illustrated in Figure 1.

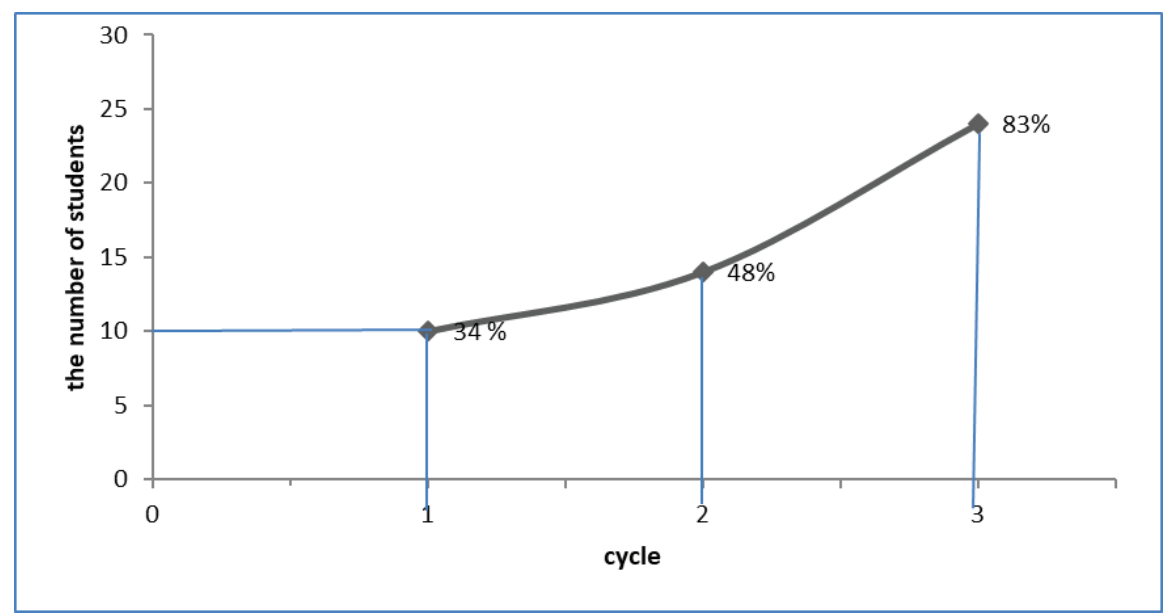

Figure 1: Learning results of narrative writing using clustering technique based on balancing brain function.

The first cycle showed that 10 of 29 students achieved over minimum mastery. The percentage of mastery in cycle 1 was 34\%. According to the success indicator in this research, the research in the first cycle did not meet the targeted success criteria. Based on the assessed aspects, two out of 29 students met good criteria in the content aspect, 22 students met good criteria in organization content, 15 students in vocabulary, eight students in grammar and 10 students in spelling. This was supported by the interviews reinforcing that the students were still unfamiliar with the guiding words from guides and clustering. The study continued into the second cycle. Further activities are expected to emphasize clusters associated with the content or storyline. Based on the implementation of the first cycle that was not successful, this second cycle used a concrete object sandals as a balancing activity of right and left-brain function. In the making of clustering the guides asked questions connected with the storyline. This was done to strengthen the content of the story. This is illustrated in Figure 2. 


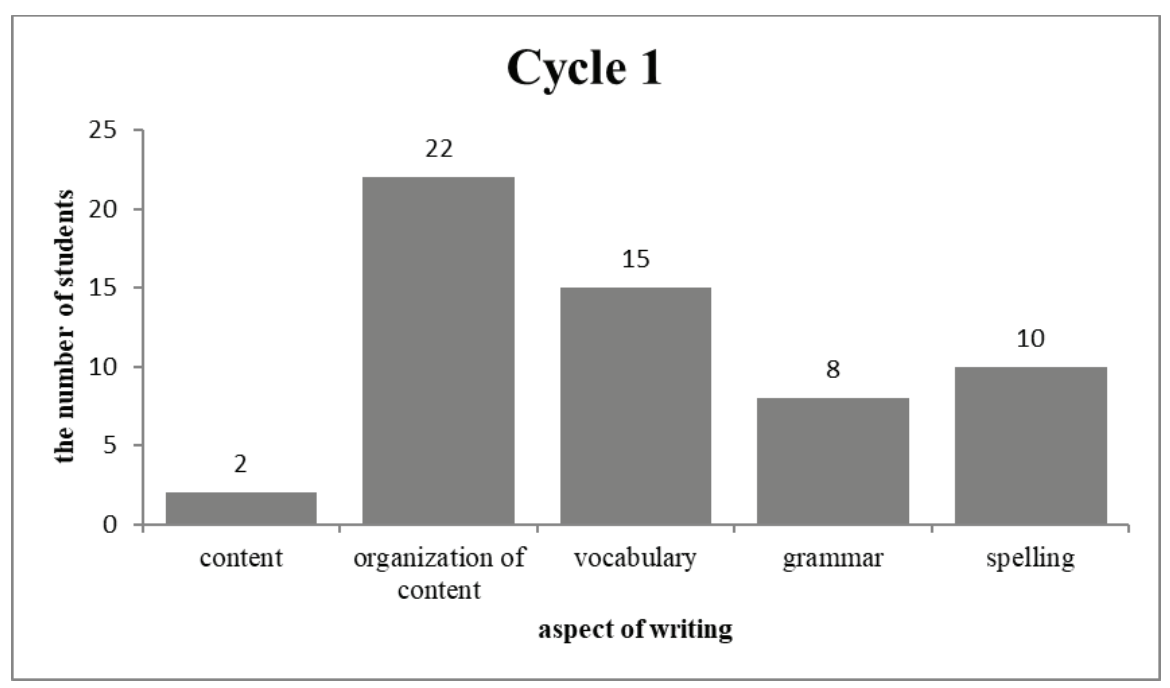

Figure 2: Results of narrative writing ability in each aspect of cycle 1.

In cycle 2 the writer used media. The use of concrete objects media sandals and making a cluster chart is a stimulation activity of the right brain. This activity is balanced with the structural activities of storyline creation. This activity is a left-brain activity. To make it easier for students to create a narrative essay the teacher conditioned the story based on sad and happy experiences. Next the teacher formed a group of sad stories and happy stories. Students developed sad or happy stories based on clustering results for sad and happy stories. By connecting the guide's question words with the storyline, the children are more fluent in writing. It was proven in cycle 2 that an increased number of students, i.e. 14, met the criteria. The percentage of mastery in cycle 1 was $48 \%$. Based on the assessed aspects, six out of 29 students met good criteria in the content aspect, 23 students met good criteria in organization content, 13 students in vocabulary, 13 students in grammar, and 10 students in spelling. This was supported by the interviews in which students expressed their feeling that concrete objects and clustering linked to the storyline help them. This is illustrated in Figure 3.

Implementation of the third cycle is via clustering technique using film media as a balancing activity of right- and left-brain function. To help students clustering is based on events that occur at the beginning of the story, during the development of the story, and at the end of the story by dividing the storyline into several events. The teacher operates the story based on sad and happy experiences. The results of the writing ability assessment in the third cycle of clustering techniques can help students to write narratives. This is proven by the increase in the number of students who met the criteria, i.e. 24 . The mastery percentage was $83 \%$. Based on the assessed aspects, 15 out of 29 students met good criteria in the content aspect, 28 students met good criteria in organization content, 27 students in vocabulary, 22 students in grammar, and 


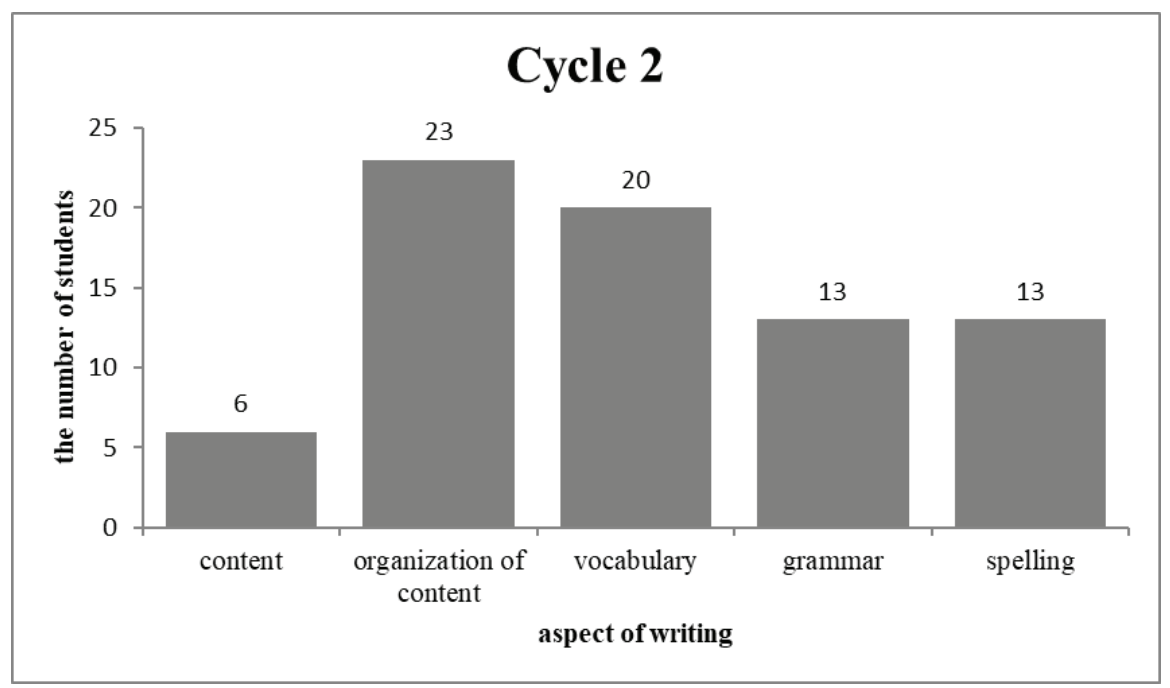

Figure 3: Results of narrative writing ability in each aspect of cycle 2.

23 students in spelling. This is illustrated in Figure 4. Figure 5 illustrates the general results of students' narrative writing skills including content, organization of content, vocabulary, grammar, and spelling using the clustering technique.

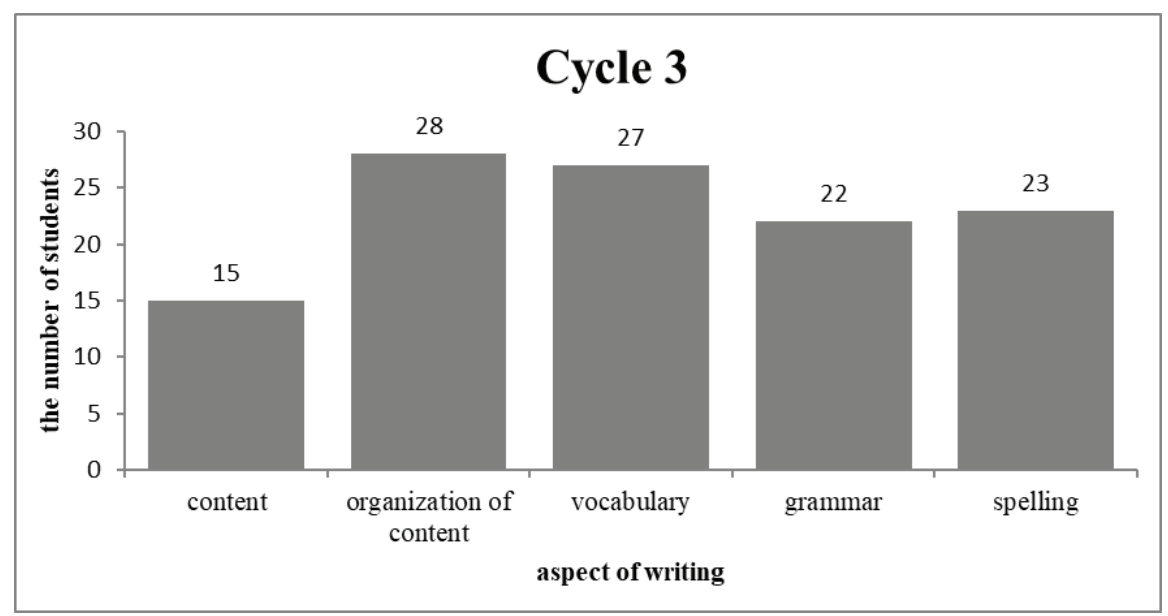

Figure 4: Results of narrative writing ability in each aspect of cycle 3.

Based on Figure 1-5, we know the development of each aspect of the assessment of narrative essays. Good early skills are found in the aspects of vocabulary, content organization, and spelling. There is an increase in development in these three aspects. This is shown by the three complete vocabulary aspect cycles of 93\% (24 students), content organization of $97 \%$ (28 students), and spelling of $79 \%$ (23 students). Clustering techniques can help students in choosing the right words, varying the vocabulary, and stringing words into a sentence. In the organizational aspects of content due to clustering that combined with the development of the storyline from the beginning 


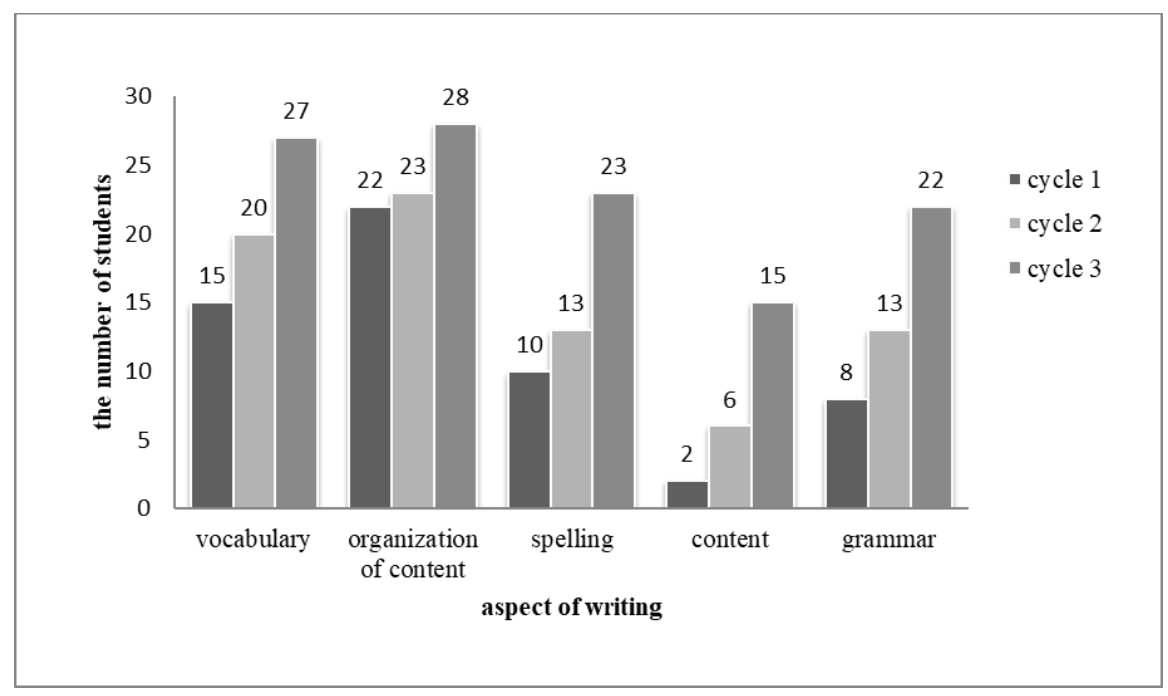

Figure 5: Results of narrative writing ability based on right- and left-brain balancing.

of the story, the content of the story and the end of the story. The use of spelling increases due to the editing stages.

The initial capability in content and grammar aspects has not been achieved maximally. However, in its development these two aspects have increased. This can be seen in the three content aspect cycle reaching 52\% (15 students) and the $76 \%$ for grammar (22 students). The contents of the ideas expressed by students are less creative; this is caused by the ability to read less than the maximum. The development of sentences in the narrative is also not maximized. This is understandable because the development of less sentence training gets enough portions. This is known when research students have difficulty in developing sentences by using this clustering technique.

The ability to write one of them is the ability to read and listening skills. Both skills support the repertoire of vocabularies, sentences, and themes, and the development of narrative story conflicts in every student. This writing ability is established through a continuous process. This requires structured training and scheduled learning time. Teachers are expected to pay attention to their acquired writing skills not instantly like memorizing cognitive-oriented test questions. Writing ability should be trained. This is in line with what Patrick and Robert say that writing is a skill that must be learned and practiced [6]. 


\section{Conclusion}

Clustering techniques by balancing brain function through various variations of image media, concrete objects, and film media can stimulate students to write narrative essays. Clustering techniques can be used as an alternative to writing narrative techniques. It has been proven that through clustering techniques, the ability of students to write narrative develops. It is necessary to draw the attention of all teachers to this so that $t$ students are able to write narrative.

\section{References}

[1] OECD: Programme for International Students Assessment (PISA). Country-Specific Overviews, Paris: OECD org; 2015.

[2] Stack M: Testing, Testing, Real All About It: Canadian Press Coverage of the PISA Result. Canadian Journal of Eduation. 2006; 29(1): 49-69.

[3] Graham S, Bollinger A, Olson CB, D'Oust C: Teaching Elementary School Students to Be Effevtive Writers. Washington, DC: National Center for Education Evaluation and Regional Assistance; 2012.

[4] Graham S: Effective Writing Instruction for All Students. USA: Renaissance Learning; 2008.

[5] Chandler D: The Act of Writing: A Media Theory Approach. Aberystwyth: University of Wales Press; 1995.

[6] Teague B, Smith P, Jimenez R: Learning to Write in a Mexican School. Journal of Language and Literacy Education. 2010; 6(1): 1-19.

[7] Tompkins GE: Teaching Writing Balancing Process and Product. New Jersey: Pearson Education; 2008.

[8] Martin SJ: Skills Acquired Throughs Personal Narrative Writing Intruction. New York: St. John Fisher College; 2010.

[9] Bartholomae D: When a writer can't write: Studies in writers blck and other composing process problems. New York: Guilford Press; 1985.

[10] Sousa DA: How the Brain Learn, $4^{\text {th }}$ edition. USA: Library of Congres Cataloging-in Publication Data; 2012.

[11] Elbow P: Embracing contraries: Explorations in learning and teaching. New York: Oxford University Press; 1986. 
[12] Smitherman CE, Girard AK: Creating Connection: Composition Theory and Creative Writing Craft in the First-Year Writing Classroom. Currents in Teaching and Learning. 2011; 3(2): 49-57.

[13] DePoter B, Mike H: Quantum Learning. New York: Dell Publishing; 1992.

[14] Rico G: Writing the Natural Way. New York: Pearson Education; 2001.

[15] Joyce B, Marsha W: Models of Teaching, $2^{\text {nd }}$ edition. New Jersey: Prentice-Hall; 1980. 